\title{
Chirality effects in jet-cooled cyclic dipeptides
}

\author{
Ariel Pérez-Mellor, Anne Zehnacker
}

\begin{abstract}
Jet-cooled bichromophoric cyclic dipeptides built on a diketopiperazine (DKP) ring are studied by combining conformer-specific vibrational spectroscopy with quantum chemical calculations. The dependence of the c-LL and c-LD dipeptides structure upon relative absolute configuration, $\mathrm{L}$ or $\mathrm{D}$, of the residues is investigated for two residues, phenylalanine (Phe) and tyrosine (Tyr). A folded-extended structure is systematically observed for all systems, like in solution or in the solid. This structure is stabilized by $\mathrm{NH} . . . \pi$ and $\mathrm{CH} . . . \pi$ interactions and shows limited stereoselectivity; the only difference between c-LL and c-LD is the nature of the $\mathrm{CH} . . . \pi$ interaction, $\mathrm{C}_{\alpha} \ldots \pi$ in c-LD and $\mathrm{C}_{\beta} \ldots \pi$ in c-LL, and a stronger NH... $\pi$ interaction in c-LD. For all studied species, the electronic excitation and the charge in the radical cation, are localized on the extended ring. The c-LL diastereomer of cyclo di-tyrosyl stands out by the existence of a stacked structure, in which formation of an $\mathrm{OH}$... O hydrogen bond stabilizes parallel aromatic rings orientation. In this structure, the electronic excitation and the major part of the charge in the cation, are localized on the $\mathrm{H}$-bond donor. The $\mathrm{OH}$... O H-bond is possible in c-LL and not c-LD, which explains the high stereoselectivity.
\end{abstract}

Keywords Chirality - Diketopiperazine - DKP- Laser spectroscopy - Supersonic expansion

Institut des Sciences Moléculaires d'Orsay (ISMO), CNRS, Univ. Paris-Sud, Université Paris-Saclay, F-91405 Orsay (France)

anne.zehnacker-rentien@u-psud.fr 


\section{Introduction}

Dipeptides with aromatic residues such as phenylalanine (Phe) or tyrosine (Tyr) spontaneously undergo intramolecular peptide bond formation in the solid phase, with concomitant loss of water.[1,2] The cyclic dipeptide formed thereby is called diketopiperazine (DKP). DKP formation sometimes is an unwanted reaction, as in overheated sweetener aspartame. $[3,4]$ However, many DKP peptides with aromatic residues have beneficial medicinal applications as antivirals, antiparasitics, anticancer therapy[5-7] or as catalysts.[8,9]

The condensed-phase structures of aromatic DKP dipeptides are very diverse. Supramolecular assemblies can form, thanks to the conjunction of hydrophobic interactions between non-polar residues and $\mathrm{NH} . . \mathrm{O}=\mathrm{C}$ hydrogen bonds between two DKP rings. Long ladder-like structures built on the repetition of a double $\mathrm{NH} \ldots \mathrm{O}=\mathrm{C}$ hydrogen bond motif are observed in cyclo diphenylalanine of natural chirality L.[10] Tyr containing dipeptides spontaneously cyclize to DKP nanotubes while the linear diphenylalanine dipeptide does to DKP nanofibrils and nanowires.[11] Determining the DKP monomer structure helps to understand the interactions that shape these nanostructures. Unless rare exceptions like cyclo diglycine, $[12,13]$ the peptide ring is non planar. Its conformation results from a compromise between the steric hindrance due to the substituents and the planarity of the amide bond. It ranges from pseudo boat or chair to intermediate twisted shapes.[14,15]

Most of the structural studies conducted so far for determining the substituents geometry rest either on NMR in solution or X-ray experiments in the solid. Bulky residues such as Phe or Tyr adopt a flagpole position of the substituent.[16,17] Steric hindrance is increased by the presence of two bulky substituents. In the cyclo diphenylalanine crystal, one of them is folded over the DKP ring in a flagpole position while the second one is extended.[18,19]

In what follows, we will focus on cyclo diphenylalanine and cyclo dityrosine, noted in short c-Phe-Phe and c-Tyr-Tyr. The chirality of the residues will be denoted by $\mathrm{L}$ and $\mathrm{D}$. The notation c-LD or c-LL will be used for discussing the common aspects of Phe and Tyr containing dipeptides. Both c-LPhe-LPhe and c-LTyr-LTyr have been studied by NMR in polar or protic solvents.[16] The results seem to point at rather symmetrical structures. However, electronic circular dichroism has suggested that c-LTyr-LTyr structures with almost parallel rings coexist with fully extended structures in solution.[20] We have undertaken the study of DKP dipeptides in different environments, either in the solid state by vibrational circular dichroism (VCD), protonated in a room-temperature ion trap, or under supersonic expansion conditions).[21-25] The aim of this study is to understand the factors that determine the structural differences between the molecule with residues of natural chirality $\mathrm{L}$ and that containing one $\mathrm{D}$ residue. This work is part of our recent studies on chirality effects in cyclic systems at low temperature.[26-29] We will describe here the spectroscopic properties of jet-cooled c-Phe-Phe and c-Tyr-Tyr, which are both built from two aromatic residues. c-Phe-Phe will serve as a model system in which the 
interaction between the two aromatic residues is mainly due to dispersion. In c-TyrTyr, the presence of the hydroxyl on the aromatic rings may cause additional interactions such as $\mathrm{OH} . . . \mathrm{O}$ or $\mathrm{OH} . . . \pi$ hydrogen bond.

The presence of the DKP ring limits the conformational freedom to the motions of the aromatic substituents. These two molecules are therefore good model systems for studying the localization of the electronic excitation in a bichromophoric system in a constrained geometry.[30-35] The question of the localization of the excitation can also be raised for vibrations and DKP dipeptides allow probing the coupling between vibrational modes in a system of well-defined geometry. The studied cyclic dipeptides are shown in Fig. 1.
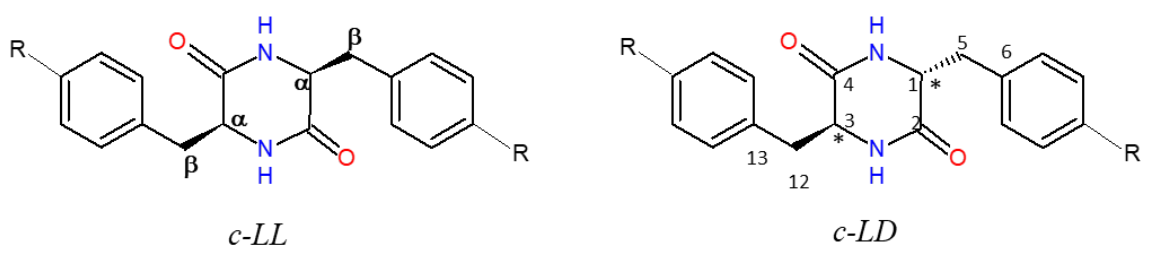

Fig. 1 Scheme of the DKP dipeptides, with atom numbering. The chiral centers are indicated by *. c-Phe-Phe: $R=H$ and c-Tyr-Tyr: $R=O H$

\section{Methodology}

\subsection{Experimental Methods}

The experimental set-up rests on a supersonic expansion equipped with a homemade laser desorption source and a time-of-flight mass spectrometer.[36,37] Argon was used as a carrier gas for sufficient cooling of the studied dipeptide. The adiabatic expansion obtained thereby results in fast efficient cooling of the internal degrees of freedom and kinetic trapping of the most stable conformers present at room temperature. The potential energy surfaces of the studied dipeptides is expected to show several minima separated by energy barriers and the conformational temperature describing the isomer population distribution is closer to room temperature rather than to the low rotational or vibrational temperature achieved in the jet.[38]

Mass-resolved $\mathrm{S}_{0}-\mathrm{S}_{1}$ spectra were obtained by one-color resonance-enhanced two-photon ionization (RE2PI) spectroscopy. Vibrational spectra were obtained using the IR-UV double resonance technique, in the $v(\mathrm{NH})$ and $v(\mathrm{OH})$ stretch region.[39,40] Fixing the UV probe on the main vibronic bands of the electronic spectrum and scanning the IR pump in the $3 \mu \mathrm{m}$ region allowed for the measurement of mass-resolved conformer-selective vibrational absorption spectra, as dip spectra in the UV probe-induced ion current. 
The IR pulse was triggered 80 ns before the UV pulse for recording the IR spectrum of the neutral molecules in their electronic ground state and $50 \mathrm{~ns}$ after for the ion. A homemade active baseline subtraction scheme was used for monitoring the IR absorption as the difference in ion signal produced by successive UV laser pulses (one without and one with the IR laser present). Additional double-resonance experiments were performed by setting the IR to the vibrational transitions observed in the vibrational spectrum and scanning the UV probe. They did not reveal new UV absorptions, which indicates that all the conformers were detected.

The dipeptides described here bear two identical chromophores and one can raise the question of the localization of the electronic transition. To answer this question, we followed the approach successfully used by Leutwyler's and Zwier's group. It rests on the symmetry breaking arising from the presence of a single ${ }^{13} \mathrm{C}$ atom in natural isotopic abundance ( $\sim 20 \%$ for molecules of this size). The RE2PI spectrum of the singly ${ }^{13} \mathrm{C}$ substituted isotopologue reflects the convolution of the exciton splitting and the site splitting due to the dissymmetry.[41-43] It corresponds to the average of the differences in the zero-point energies (ZPE) between all ${ }^{12} \mathrm{C}$ molecules and those containing one ${ }^{13} \mathrm{C}$. Statistically, the probability for the ${ }^{13} \mathrm{C}$ to be located one of the aromatic rings ( 12 carbon atoms) is much larger than that of being located on the peptide ring ( 4 carbon atoms). We can therefore assume that the two bands of the doublet correspond to the excitation of the all ${ }^{12} \mathrm{C}$ ring and of that containing ${ }^{13} \mathrm{C}$.

The peptides under study were purchased from Novopep Limited (Shanghai China) and used without further purification.

\subsection{Theoretical Methods}

DKP cyclic dipeptides display a complex conformational landscape due to the possible orientation of the aromatic substituents. The potential energy surface of cLPhe-LPhe and c-LPhe-DPhe was explored using the OPLS-2005 force field combined with the advanced conformational search implemented in the MacroModel program of the Schrödinger package.[44] The potential energy surface of c-LTyrLTyr and c LTyr-DTyr was then manually explored, starting from the six local minima obtained for c-Phe-Phe. All local minima found thereby were fully optimized within the frame of the DFT theory using the dispersion-corrected functional B3LYP-D3[45,46] associated with the Pople 6-311++g(d,p) split-valence basis set.[47] This level of theory satisfactorily accounts for the vibrational spectroscopy of similar systems at an acceptable calculation cost. $[48,21,24]$ In particular, inclusion of dispersion is important for aromatic bichromophoric species.[45,46] The charge distribution was obtained from the Natural Bond Orbital (NBO) analysis.[49] The electronic excited state energies were calculated by the time-dependent DFT (TD-DFT) method for the first ten singlet excited states, at the WB97XD/augcc-pVDZ level of theory. This level satisfactory describes the electronic excited 
states of aromatic molecules.[50,51] The vertical ionization energy was calculated at the unrestricted-DFT/B3LYP level.

Optimization of the radical cation was performed at the same level of theory as the neutrals by removing an electron from the calculated neutral forms, which reflects the vertical ionization process.

The vibrational frequencies were first calculated within the frame of the harmonic approximation at the same level of theory. The absence of imaginary frequency was checked for all local minima found. The structural differences between diastereoisomers are often subtle[36,52] and the definite assignment of the observed structures rests on a reliable comparison between observed and simulated spectra in the region of $3 \mu \mathrm{m}$. To this end, one can resort to several strategies. The most commonly used is to use tabulated or empirical scaling factors to account for anharmonicity and basis set incompleteness. [53] Better agreement between experimental and simulated spectra is obtained when using mode-dependent scaling factors based on an extensive library of similar systems. [54,55] An additional difficulty comes from the fact that combination bands or overtones of the amide I and II modes, i.e. $\mathrm{v}(\mathrm{CO})$ and $\beta(\mathrm{NH})$, appear in this region. [56] Description of the vibrational modes beyond the harmonic approximation is therefore desirable. An efficient but computationally expensive approach is full anharmonic calculations using the variational perturbation theory.[57-59] To circumvent the computational cost, one can also limit the calculations to relevant selected modes. It gives similar results if the modes are carefully selected. Another compromise between accuracy and computational cost is to define the scaling factor as the slope of the linear regression between harmonic and anharmonic frequencies, for all the computed structures of a given molecule. This results in different scaling factors for different spectral ranges. For example, full harmonic calculations were performed for the model system cyclo tyrosyl proline.[23] The scaling factor for the fingerprint, the $v(\mathrm{CH})$, and the $v(\mathrm{NH}) / v(\mathrm{OH})$ region is $0.977,0.957,0.953$, respectively. The scaling factors are usually similar for molecules of similar structure: in the case of cyclo Phe-Phe, the scaling factor defined from the ration between mode-selected anharmonic frequencies and harmonic ones is 0.952 in the $v(\mathrm{OH})$ and $v(\mathrm{NH})$ stretch region.

In what follows, we will use the full anharmonic frequencies calculations for the most stable structures of c-Phe-Phe. In parallel, anharmonic frequencies including only $v(\mathrm{OH})$ and $v(\mathrm{NH})$ stretches were computed for all the structures of c-Phe-Phe and c-Tyr-Tyr. In the case of c-Phe-Phe, the agreement between full or selected modes calculation and the experiment is excellent. Less satisfactory agreement is obtained for c-Tyr-Tyr, probably because the modes included in the calculations are not sufficient. We will therefore use the harmonic frequencies scaled by 0.952 for the latter. The harmonic frequencies given in the text and tables include the scaling factor. All calculations were performed with the Gaussian 09 package.[60] 


\section{Results and Discussion}

\subsection{Nomenclature of the Studied Systems}

The DKP ring has limited conformational mobility; the most important parameters defining the dipeptides geometry are related to the orientation of the aromatic substituent relative to the amide bond (Fig. 2). Three geometries are minima of the potential energy surface: two gauche geometries, $\mathrm{g}^{+}$and $\mathrm{g}^{-}$correspond to dihedral angles $\tau_{1}\left(\mathrm{~N} \mathrm{C}_{1} \mathrm{C}_{5} \mathrm{C}_{6}\right)$ and $\tau_{2}\left(\mathrm{~N} \mathrm{C}_{3} \mathrm{C}_{12} \mathrm{C}_{13}\right)$ of $\sim 60^{\circ}$ and $-60^{\circ}$ for the $\mathrm{L}$ residue, respectively, with opposite sign of the angles for the $\mathrm{D}$ residue. The trans $\mathrm{t}$ geometry corresponds to $\tau_{1}$ and $\tau_{2}$ angles of $\sim 180^{\circ}$. For c-Tyr-Tyr, an additional parameter describes the orientation of the tyrosine hydroxyls relative to the DKP ring, I and II (see Fig. 2). For each benzyl substituent orientation, the number of isomers is thus multiplied by four in c-Tyr-Tyr relative to c-Phe-Phe. The nomenclature used in what follows starts with "c-" for the cyclic nature of the peptide, followed by the orientation of the substituent $\mathrm{g}^{+}, \mathrm{g}^{-}$, or $\mathrm{t}$. L or D in subscript denotes the configuration of each residue. In the case of c-Tyr-Tyr, it is followed by I or II for the tyrosyl $\mathrm{OH}$ positions.

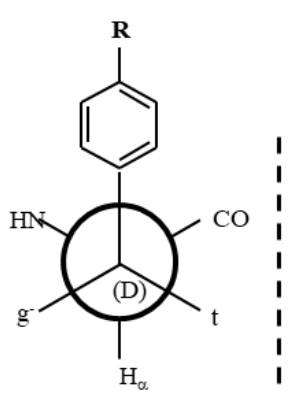

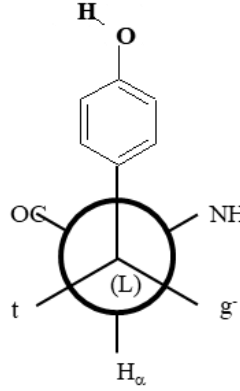

Type I

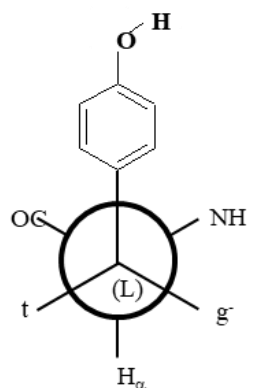

Type II

Fig. 2 Nomenclature for the aromatic substituent conformation in a D residue (left) or an $L$ residue (right). In all the schemes, the substituent is in $g^{+}$conformation. The two other possible orientations are indicated by the corresponding letters $t$ and $g$ - Nomenclature for the hydroxyl substituent orientation: anticlockwise (type I) orientation of the hydroxyl group in a Newman projection or clockwise orientation (type II)

\subsection{Symmetry Properties}

Particular symmetry properties arise from the fact that the DKP dipeptides studied here are made of two identical residues, as it is the case for the simple model cyclo diglycine. The latter is not chiral and possesses $C_{i}$ symmetry because the DKP 
ring is planar.[12] In the systems studied here, the presence of substituents is the cause of dissymmetry. First, the DKP ring becomes out of plane to accommodate the bulky aromatic rings, which has consequences on the symmetry of the system. In contrast with planar cyclo diglycine for which the two $\mathrm{H}$ atoms are in equivalent positions, the substituents of the $\mathrm{C}_{\alpha}$ carbons now occupy distinct positions, axial and equatorial.[61]

From the stereochemical point of view, chirality is introduced by substituting the $\mathrm{C}_{\alpha}$ atoms $\left(\mathrm{C}_{1}^{\alpha}\right.$ and $\left.\mathrm{C}_{3}^{\alpha}\right)$ by benzyl (c-Phe-Phe) or hydroxybenzyl (c-Tyr-Tyr). The molecules therefore exist as four stereoisomers. In c-LL, the two substituents are both in equatorial or axial positions. The DKP ring itself may belong to the $\mathrm{C}_{2}$ or $\mathrm{C}_{1}$ (no symmetry) point group. All the $\mathrm{C}_{1}$ or $\mathrm{C}_{2}$ conformations are chiral and their enantiomer is their mirror image, c-DD.

In c-LD, one of the substituents is in equatorial, and the other is in axial position. As the two residues have opposite chirality, c-LD can be seen at first sight as a meso compound, which is not chiral. The DKP ring may have $\mathrm{C}_{\mathrm{i}}$ symmetry, or no symmetry $\left(\mathrm{C}_{1}\right)$. Indeed, $\mathrm{C}_{\mathrm{i}}$ conformers are not chiral, for example cyclo D-alanyl-Lalanine has planar DKP ring and $\mathrm{C}_{\mathrm{i}}$ symmetry.[13] In contrast, $\mathrm{C}_{1}$ geometries are chiral because the two aromatic substituents have non-equivalent orientations. This happens when dissymmetry is brought about by the interaction between the two residues. This type of chirality is transient at room temperature but is frozen under supersonic expansion conditions. The dissymmetric structures therefore exist as pairs of non-superimposable mirror images under supersonic jet conditions, c-LD and c-DL. We will limit the discussion to the former in what follows. As will be seen later, all local minima of c-LD are non-symmetrical. The non-chiral $C_{i}$ structures are transition states. This contrasts with c-LL for which some of the local minima belong to the $\mathrm{C}_{2}$ symmetry point group, as described in what follows.

\subsection{Theoretical Results}

\subsubsection{Calculated Structure in the Ground Electronic State}

The calculated structures are separated into six families resulting from the combination of the $\mathrm{g}^{+}, \mathrm{g}^{-}$, and $\mathrm{t}$ orientations of the aromatic substituents, defined by the angles $\tau_{1}$ and $\tau_{2}$ introduced above. We will limit the discussion to the most stable families, shown in Fig. 3. We will also discuss the pseudo equatorial or pseudo axial position of the benzyl substituents. The orientation of the tyrosine $\mathrm{OH}$ increases the number of conformers in c-Tyr-Tyr, without modifying neither the energetics nor the spectroscopy, except in the stacked conformation described below. This is reminiscent of the amino acid tyrosine whose conformers due to hydroxyl rotation cannot be discriminated by their IR signature $[62,63]$. This is why we will discuss the calculated structures in terms of families that include the four $\mathrm{OH}$ orientations. 
c- $g^{+} g^{-}$("Folded-Extended") structures: This geometry is asymmetric, with the substituents in dissymmetric orientations: the $\mathrm{g}^{+}$aromatic ring is folded over the amide bond and $\mathrm{g}^{-}$is extended out of the DKP ring, which results to stabilizing combination of $\mathrm{CH} \ldots \pi$ and $\mathrm{NH} . . . \pi$ interactions. The DKP geometry is in a twisted boat conformation. The $\mathrm{c}-\mathrm{g}_{\mathrm{L}}^{+} \mathrm{g}_{\mathrm{L}}^{-}$structure of $\mathrm{c}-\mathrm{LL}$ is stabilized by $\mathrm{C}_{12} \mathrm{H} \ldots \pi$ interaction and a weak $\mathrm{NH} . . . \pi$ interaction. Both substituents, in particular the folded one, are in pseudo-axial position. For the $\mathrm{c}_{-} \mathrm{g}_{\mathrm{L}}^{+} \mathrm{g}_{\mathrm{D}}^{-}$conformer of $\mathrm{c}-\mathrm{LD}$, the pseudo axial folded $\mathrm{L}$ residue acts as an acceptor in the $\mathrm{C}_{3} \mathrm{H} \ldots \pi$ interaction, while the extended $\mathrm{D}$ residue is equatorial and acts as the donor. Whatever the chirality, the pseudo axial orientation of the folded substituent is of prime importance as it allows formation of the secondary $\mathrm{CH} . . . \pi$ and $\mathrm{NH} . . . \pi$ interactions.

The "folded-extended" geometry c-g ${ }^{+} \mathrm{g}^{-}$is the most stable structure in all systems. It is more stable by $1.3 \mathrm{kcal} / \mathrm{mol}$ and contributes by more than $90 \%$ to the total population of c-LPhe-LPhe. The energetic advantage is slightly less $(0.95 \mathrm{kcal} / \mathrm{mol})$

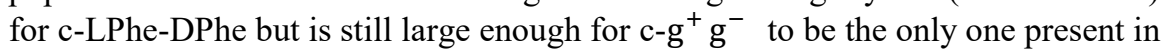
the jet. The energy of the four $\mathrm{c}-\mathrm{g}_{\mathrm{L}}^{+} \mathrm{g}_{\mathrm{L}}^{-}$conformers is the same within $0.3 \mathrm{kcal} / \mathrm{mol}$ in c-Tyr-Tyr and they are probably all present in the supersonic expansion. Altogether, $\mathrm{c}-\mathrm{g}_{\mathrm{L}}^{+} \mathrm{g}_{\mathrm{D}}^{-}$conformers account for $80 \%$ of the population of c-LTyr-DTyr. However, c-LTyr-LTyr stands out as $\mathrm{c}-\mathrm{g}_{\mathrm{L}}^{+} \mathrm{g}_{\mathrm{L}}^{-}$conformers only amount to $\sim 60 \%$ of the total population, a point to which we shall return later.

The c-g ${ }^{+} \mathrm{g}^{-}$("Folded-Extended") structures show little dependence upon chirality of the residues. However, the fact that both residues have identical or opposite chirality changes the nature of the $\mathrm{CH} . . \pi$ interaction. In $\mathrm{c}-\mathrm{LD}$, due to the equatorial nature of the extended $\mathrm{g}^{-}$substituent, there is a $\mathrm{C}_{\alpha} \mathrm{H} \ldots \pi$ interaction in $\mathrm{c}_{-} \mathrm{g}_{\mathrm{L}}^{+} \mathrm{g}_{\mathrm{D}}^{-}$while two axial substituents in c-LL result to $\mathrm{C}_{\beta} \mathrm{H} \ldots \pi$ interaction in $\mathrm{c}-\mathrm{g}_{\mathrm{L}}^{+} \mathrm{g}_{\mathrm{L}}^{-}$. In addition, the $\mathrm{NH} \ldots \pi$ interaction is slightly stronger in $\mathrm{c}_{-} \mathrm{g}_{\mathrm{L}}^{+} \mathrm{g}_{\mathrm{D}}^{-}$as indicated by the $\mathrm{N}_{2} \mathrm{H} \ldots \pi$ distance, shorter in $\mathrm{c}-\mathrm{g}_{\mathrm{L}}^{+} \mathrm{g}_{\mathrm{D}}^{-}$than in $\mathrm{c}-\mathrm{g}_{\mathrm{L}}^{+} \mathrm{g}_{\mathrm{L}}^{-}$by $\sim 0.06 \AA$.

c- $g^{-} g^{-}$("Fully-Extended") structures: They have $\mathrm{C}_{2}$ symmetry in c-LL, thus, the two benzyl substituents are equivalent. In $\mathrm{c}-\mathrm{g}_{\mathrm{L}}^{-} \mathrm{g}_{\mathrm{L}}^{-}$, both aromatic rings, in axial position, are fully extended. The equivalent structure in $\mathrm{c}-\mathrm{LD}, \mathrm{c}-\mathrm{g}_{\mathrm{L}}^{-} \mathrm{g}_{\mathrm{D}}^{-}$, only shows minor differences in the position of the phenyl rings related to the fact that one residue is in axial and the other in equatorial position. Fully extended structures are higher in energy by at least $1.8 \mathrm{kcal} / \mathrm{mol}$ in all the systems and will not be discussed further. Their relative energy illustrates the importance of correctly including dispersion, as expected in a system with two strongly polarizable aromatic rings. Non-inclusion of dispersion stabilizes the extended structures that become the most stable, which is in contradiction to the experimental results. 

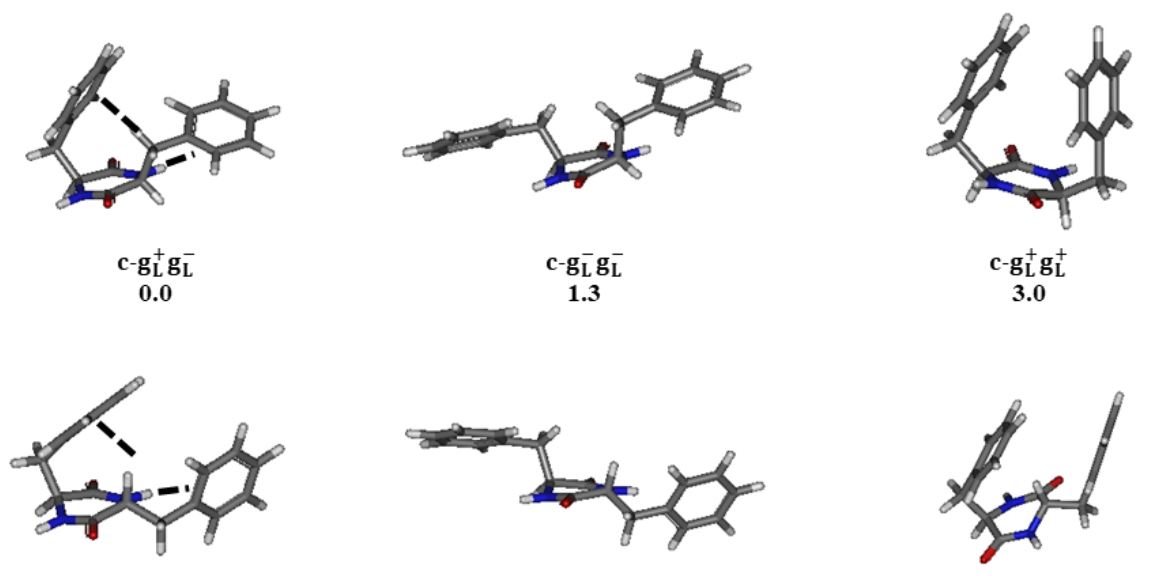

$\underset{(0.0)}{c-g_{L}^{+} g_{D}^{-}}$

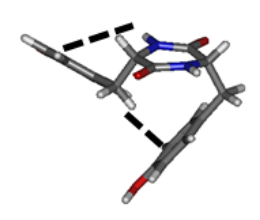

c- $\mathrm{g}_{\mathrm{LII}}^{+} \mathbf{g}_{\mathrm{LI}}^{-}$

(0.0)

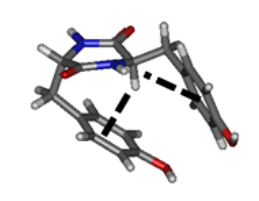

c-g LII $_{\text {DI }}^{-}$
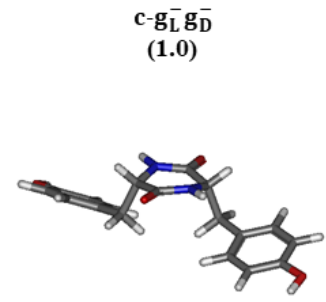

c- $\mathrm{g}_{\mathrm{LI}}^{-} \mathrm{g}_{\mathrm{LI}}^{-}$

(1.8)

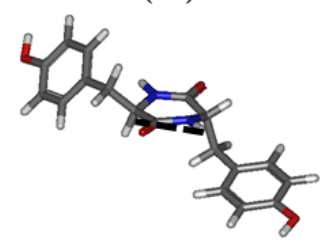

$c-\mathrm{g}_{\mathrm{LI}}^{-} \mathrm{g}_{\mathrm{DI}}^{-}$

(1.2)
$\underset{(2.9)}{c-g_{L}^{+} t_{D}}$

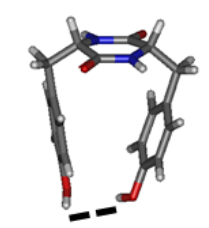

c-g-g ${ }_{\text {LI }}^{+} \mathrm{g}_{\mathrm{LI}}^{+}$

(0.2)

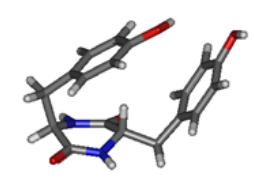

c-t $\mathrm{t}_{\mathrm{LI}} g_{\mathrm{DII}}^{+}$

(2.1)

Fig. 3 Structures of c-Phe-Phe and cTyr-Tyr. The relative energy is given in parentheses in $\mathrm{kcal} / \mathrm{mol}$

$c-g_{S}^{+} g_{S}^{+}$("Stacked") structures: They also belong to the $\mathrm{C}_{2}$ symmetry point group for c-LL. The equatorial position is favored over axial as it releases the repulsion arising from parallel benzene rings. Still, c- $\mathrm{g}_{\mathrm{SL}}^{+} \mathrm{g}_{\mathrm{SL}}^{+}$lies $3 \mathrm{kcal} / \mathrm{mol}$ higher in energy than the most stable form in c-LPhe-LPhe. Indeed, dispersion is the only 
stabilizing interaction there and cannot counterbalance the expected repulsion between the benzene rings. In c-LPhe-DPhe, $\mathrm{c}^{-} \mathrm{g}_{\mathrm{L}}^{+} \mathrm{g}_{\mathrm{L}}^{+}$is not a stacked geometry because the two substituents cannot be both in equatorial position. The geometry with maximum interaction between the aromatic rings is $\mathrm{c}-\mathrm{g}_{\mathrm{L}}^{+} \mathrm{t}_{\mathrm{D}}$. Its relative energy exceeds $2 \mathrm{kcal} / \mathrm{mol}$ for c-Phe-Phe and c-Tyr-Tyr and we will not discuss it further. The energetics of the stacked structures are completely different in c-LTyr-LTyr. The stacked $\mathrm{c}-\mathrm{g}_{\mathrm{L}}^{+} \mathrm{g}_{\mathrm{L}}^{+}$geometry facilitates the interaction between the two hydroxyls, which stabilizes this structure. For example, the Gibbs energy of c- $\mathrm{g}_{\mathrm{LI}}^{+} \mathrm{g}_{\mathrm{LI}}^{+}$is as low as $0.2 \mathrm{kcal} / \mathrm{mol}$. In contrast with the other structures, the orientation of the $\mathrm{OHs}$ slightly influences the energetics. In c- $\mathrm{g}_{\mathrm{LI}}^{+} \mathrm{g}_{\mathrm{LI}}^{+}$, the two $\mathrm{OH}$ groups show antiparallel orientation of their electric dipoles and mostly interact through dipole-dipole interaction, as described for amide stacking in $\gamma$-peptides.[64] $\mathrm{c}_{-\mathrm{LLI}}^{+} \mathrm{g}_{\mathrm{LII}}^{+}$differs from c$\mathrm{g}_{\mathrm{LI}}^{+} \mathrm{g}_{\mathrm{LI}}^{+}$by the parallel orientation of the two $\mathrm{OH}$ that favors $\mathrm{OH}$... O hydrogen bond formation. It is interesting to note that the dipole-dipole interaction is competitive with the hydrogen bond formation and that these two structures are almost isoenergetic. However, c- $\mathrm{g}_{\mathrm{LI}}^{+} \mathrm{g}_{\mathrm{LII}}^{+}$reproduces the experimental better than c- $\mathrm{g}_{\mathrm{LI}}^{+} \mathrm{g}_{\mathrm{LI}}^{+}$, as described later.

Interestingly, the most stable conformer of c-LL is always more stable than the most stable conformer of c-LD, by $0.4 \mathrm{kcal} / \mathrm{mol}$ for c-Phe-Phe and $2.0 \mathrm{kcal} / \mathrm{mol}$ for c-Tyr-Tyr.

\subsubsection{Calculated Structure in the Cation}

Optimization of the cation of c-Phe-Phe indicates charge localization on the nitrogen atoms. For this reason, the NH stretches are shifted down in energy and not observed experimentally. We have therefore focused on c-LTyr-LTyr and c-LTyr-DTyr. The calculated structures of their cations are shown in

Fig. 4. Starting points for the optimization are the most stable neutral "foldedextended" structures c- $\mathrm{g}_{\mathrm{LI}}^{+} \mathrm{g}_{\mathrm{LI}}^{-}$and c- $\mathrm{g}_{\mathrm{LI}}^{+} \mathrm{g}_{\mathrm{DI}}^{-}$, and the "stacked" geometry of c-LTyrLTyr, c-g $\mathrm{gL}_{\mathrm{LI}}^{+} \mathrm{g}_{\mathrm{LI}}^{+}$, reflecting the vertical ionization process. For the "folded-extended" structure, the main difference relative to the neutral is that the $\mathrm{g}^{-}$conformation of the extended benzyl is not stable in the ion. Instead, the $\mathrm{g}^{-}$aromatic ring undergoes rotation towards a $t$ conformation. This leads to the $\mathrm{c}_{\mathrm{inn}} \mathrm{g}^{+} \mathrm{t}$ structure. Indeed, the $\mathrm{NH} . . . \pi$ interaction in the neutral becomes repulsive in the ion and is replaced by an interaction between the amide $\mathrm{CO}$ and the positively charged aromatic ring.

The geometry of the stacked conformer c- $\mathrm{g}_{\mathrm{LI}}^{+} \mathrm{g}_{\mathrm{LII}}^{+}$is not much modified upon ionization, except the $\mathrm{OH}$...O distance, which is considerably shorter in the ion $(1.94$ vs. $2.23 \AA$ Á). The stronger $\mathrm{H}$-bond associated with this shorter distance stabilizes the hydrogen-bonded form $\mathrm{c}_{\text {ion }}-\mathrm{g}_{\mathrm{LI}}^{+} \mathrm{g}_{\mathrm{LII}}^{+}$by $2.7 \mathrm{kcal} / \mathrm{mol}$ relative to $\mathrm{c}-\mathrm{g}_{\mathrm{LII}}^{+} \mathrm{t}_{\mathrm{LI}}$.

The NBO charges distribution, given in

Fig. 4, is very dissymmetrical. In the folded - extended structures, $\mathrm{c}_{\text {ion }}-\mathrm{g}^{+} \mathrm{t}$, most of the charge is on the extended $\mathrm{g}_{\mathrm{LI}}^{+}$benzyl. Then, the $v(\mathrm{OH})$ stretch frequency of 
the folded tyrosyl is similar to that in the neutral. The rest of the charge is mainly borne by $\mathrm{C}_{\alpha} \mathrm{H}$ groups. Interestingly, the amide bonds are neutral.

The charge of the hydrogen-bonded cation $\mathrm{c}_{\text {ion }}-\mathrm{g}_{\mathrm{LI}}^{+} \mathrm{g}_{\mathrm{LII}}^{+}$is distributed on both aromatic rings. Still, it is dissymmetric, being 0.654 on the H-bond donor vs. 0.232 on the acceptor. Thus, the $v(\mathrm{OH})$ stretch frequency of the H-bond acceptor is less shifted relative to the neutral than that of the donor. We will keep these remarks in mind when discussing the vibrational spectroscopy of the cation.

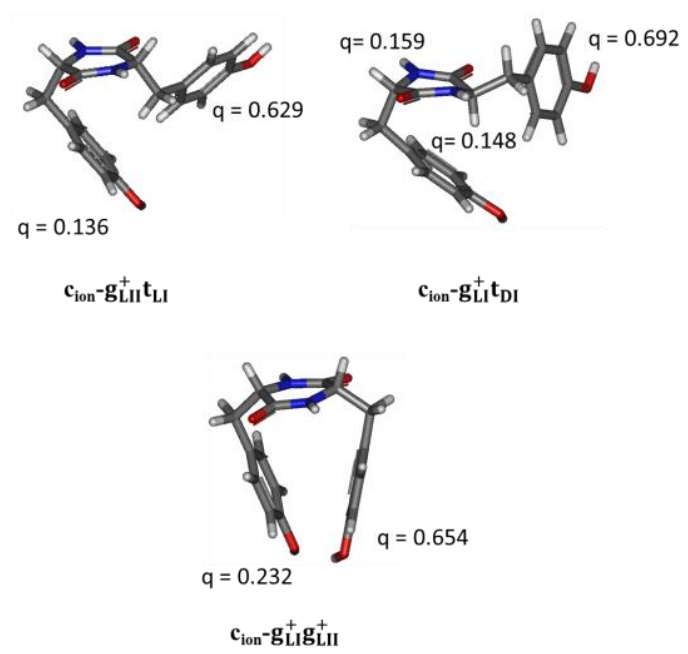

Fig. 4 Calculated structure of the c-Tyr-Tyr cations, together with the charges on the aromatic rings and the $C_{a} H$ groups. Only charges larger than 0.1 are indicated

\subsection{Experimental Results}

\subsubsection{Electronic Spectroscopy}

The electronic spectra are shown in

Fig. 5 and Fig. 6. That of c-Phe-Phe

Fig. 5) shows a simple vibronic pattern, almost identical for c-LPhe-Lhe and cLPhe-DPhe. It shows an intense origin located at very similar energies, $37603 \mathrm{~cm}^{-1}$ and $37600 \mathrm{~cm}^{-1}$ for c-LPhe-LPhe and c-LPhe-DPhe, respectively, in the region of the phenylalanine monomer.[65-67] It is followed by a strong Hertzberg-Teller al- 
lowed transition at 532 and $529 \mathrm{~cm}^{-1}$ for c-LPhe-LPhe and c-LPhe-DPhe, respectively. Almost no other vibronic activity is observed. These spectra indicate similar rigid structures for the two diastereomers.
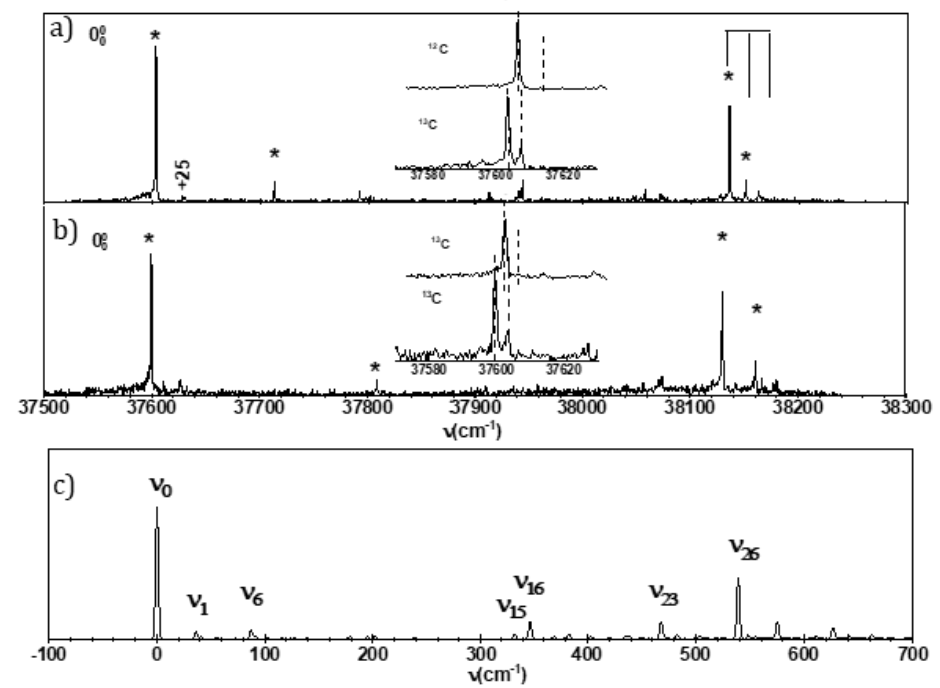

Fig. 5 RE2PI Electronic spectrum of a) c-LPhe-LPhe b) c-LPhe-DPhe. The inset shows the comparison between the origin recorded at the mass of all ${ }^{12} \mathrm{C} c$-Phe-Phe and at the mass of a single ${ }^{13} \mathrm{C} c$-Phe-Phe. The ${ }^{13} \mathrm{C}$ spectrum is multiplied by 5 . The calculated frequencies are labelled by $v_{n} . v_{26}$ is the Herzberg-Teller allowed mode. The bands probed by the UV laser for measuring the IR spectra are indicated by *. Adapted from Ref.24 (licence 4551230911971) with permission from Elsevier

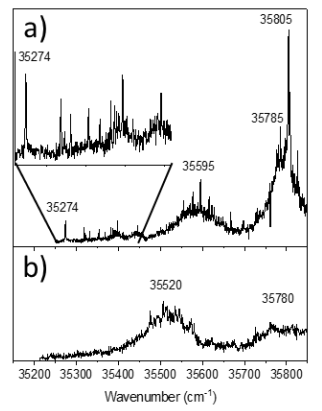

Fig. 6. RE2PI electronic spectrum of a) c-LTyr-LTyr b) c-LTyr-DTyr. The bands probed by the UV laser for measuring the IR dip spectra are indicated by their frequency. Adapted and reproduced from Ref. 22 with permission from the Royal Society of Chemistry 
As observed for c-Phe-Phe, the spectrum of c-Tyr-Tyr appears in the region of the amino acid monomer. However, it contrasts strongly with that of c-Phe-Phe. c-LTyr-DTyr only shows a featureless absorption with two maxima at 35500 and 35800 , which is assigned to a species denoted $\mathrm{B}_{\mathrm{c}-\mathrm{LD}}$ (Fig. 6). The spectrum of cLTyr-LTyr shows similar broad maxima, at $\sim 35600$ and $35800 \mathrm{~cm}^{-1}$, assigned to a species denoted $\mathrm{B}_{\mathrm{c}-\mathrm{LL}}$, and superimposed with narrow lines, with an origin at 35274 $\mathrm{cm}^{-1}$, assigned to a species denoted $\mathrm{A}_{\mathrm{c}-\mathrm{LL}}$. We exclude that the broad absorption arises from non-radiative processes in the electronic excited state because the spectra of cold tyrosine or protonated tyrosine are well resolved.[68,69,63] A more likely hypothesis is spectral congestion and/or insufficient cooling due to $\mathrm{OH}$ isomerism.

\subsubsection{Vibrational spectroscopy and assignment}

$\mathbf{c}-\boldsymbol{g}^{+} \boldsymbol{g}^{-}$Structures: Identical IR-UV spectra are obtained whatever the band probed in the RE2PI spectrum of c-LPhe-LPhe or c-LPhe-DPhe, which indicates the presence of a single conformer under supersonic jet conditions. c-LPhe-LPhe and c-LPhe-DPhe show similar spectroscopic signatures with a triplet at 3393$3407-3416 \mathrm{~cm}^{-1}$ for c-LPhe-LPhe and at $3386-3417-3424 \mathrm{~cm}^{-1}$ for c-LPhe-DPhe. The different frequencies for the $v(\mathrm{NH})$ stretch point at dissymmetric structures. We will therefore discard the $\mathrm{C}_{2}$ structures for the assignment and focus on the most stable "folded-extended" c- $\mathrm{g}_{\mathrm{L}}^{+} \mathrm{g}_{\mathrm{L}}^{-}$and $\mathrm{c}-\mathrm{g}_{\mathrm{L}}^{+} \mathrm{g}_{\mathrm{D}}^{-}$, structures. Fig. 7 shows the comparison between the experimental spectra and those resulting from the anharmonic fre-

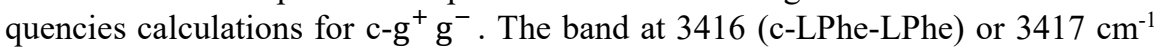
(c-LPhe-DPhe) is assigned to the free $v(\mathrm{NH})$ stretch of the $\mathrm{g}^{+}$extended benzyl, perfectly reproduced by the anharmonic calculations at $3411 \mathrm{~cm}^{-1}\left(\mathrm{c}-\mathrm{g}_{\mathrm{L}}^{+} \mathrm{g}_{\mathrm{L}}^{-}\right)$and 3412 $\mathrm{cm}^{-1}\left(\mathrm{c}-\mathrm{g}_{\mathrm{L}}^{+} \mathrm{g}_{\mathrm{D}}^{-}\right)$.

The lower-energy band at $3393 \mathrm{~cm}^{-1}\left(\mathrm{c}-\mathrm{g}_{\mathrm{L}}^{+} \mathrm{g}_{\mathrm{L}}^{-}\right)$or $3386 \mathrm{~cm}^{-1}\left(\mathrm{c}-\mathrm{g}_{\mathrm{L}}^{+} \mathrm{g}_{\mathrm{D}}^{-}\right)$is assigned to the $v(\mathrm{NH})$ stretch of the $\mathrm{g}^{-}$folded benzyl, involved in the $\mathrm{NH} . . . \pi$ interaction. The downshift of the frequency is very well reproduced by the anharmonic calculations that yield $3392 \mathrm{~cm}^{-1}$ for $\left(\mathrm{c}-\mathrm{g}_{\mathrm{L}}^{+} \mathrm{g}_{\mathrm{L}}^{-}\right)$and $3387 \mathrm{~cm}^{-1}$ for $\left(\mathrm{c}-\mathrm{g}_{\mathrm{L}}^{+} \mathrm{g}_{\mathrm{D}}^{-}\right)$.

For all systems studied here, a third band appears in the $v(\mathrm{NH})$ stretch region, the intensity of which decreases more rapidly than that of the others when reducing the laser power. It can be explained by taking into account overtones or combination bands involving the $v(\mathrm{CO})$ stretch and the $\beta(\mathrm{NH})$ bend. In $\mathrm{c}-\mathrm{g}_{\mathrm{L}}^{+} \mathrm{g}_{\mathrm{L}}^{-}$the two $v(\mathrm{CO})$ stretches are uncoupled and calculated at different frequencies, the lower-energy band at $1705 \mathrm{~cm}^{-1}$ corresponds to the $\mathrm{CO}$ of the amide interacting with the folded benzyl and the high-energy $v(\mathrm{CO})$ at $1713 \mathrm{~cm}^{-1}$ to the other one. Anharmonic calculations predict active $v(\mathrm{CO})$ overtones at $3395 \mathrm{~cm}^{-1}$ and $3410 \mathrm{~cm}^{-1}$, in the vicinity of the $v(\mathrm{NH})$ stretch. They could be responsible for the band at $3407 \mathrm{~cm}^{-1}$.

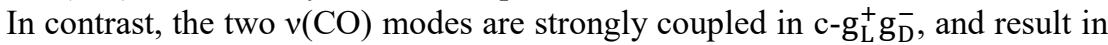
a forbidden symmetric mode at $1714 \mathrm{~cm}^{-1}$ and a strongly allowed asymmetric mode at $1716 \mathrm{~cm}^{-1}$. Anharmonic calculations predict an intense combination band of the 
two $v(\mathrm{CO})$ stretches at $3413 \mathrm{~cm}^{-1}$, in resonance with the free $v(\mathrm{NH})$. It could be responsible for the band at $3424 \mathrm{~cm}^{-1}$. Such intense combination bands or overtones have been observed already in dipeptides, including those built on the diketopiperazine ring[70] or $\beta$ sheets models.[56]
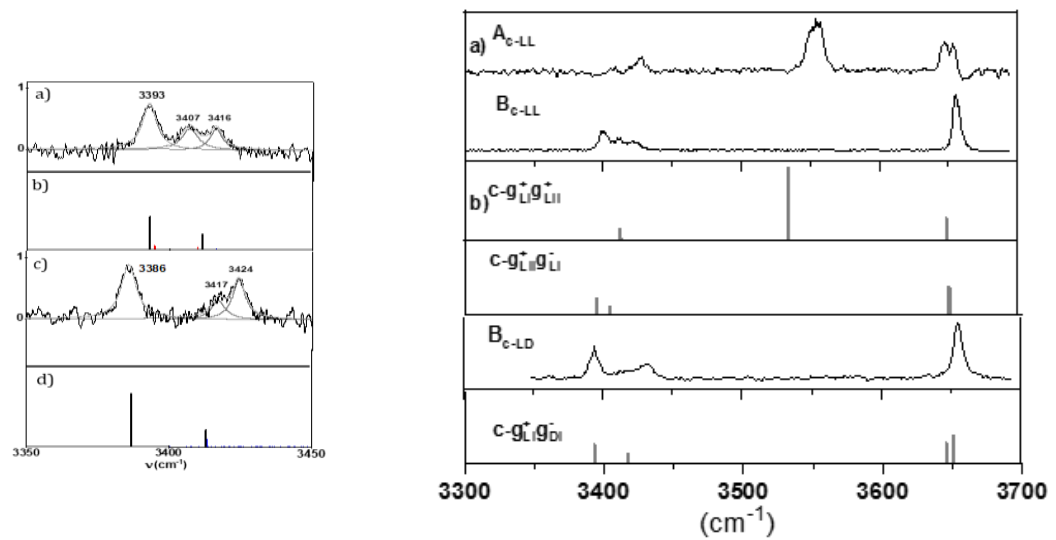

Fig. 7 Comparison between the IR-UV spectra and those of the structures to which they are assigned for $c$-Phe-Phe (left) and c-Tyr-Tyr (right). a) c-LL experimental spectra b) calculated spectra for $c-L L$. c) $c-L D$ experimental spectra. d) calculated spectra for $c-L D$. Adapted and reproduced from Ref. 22 with permission from the Royal Society of Chemistry. Adapted and reprinted Ref.24 (licence 4551230911971) with permission from Elsevier

Similar vibrational spectra are observed in the $v(\mathrm{NH})$ stretch region when setting the probe on the broad absorption observed in the RE2PI spectra of c-LTyr-LTyr and c-LTyr-DTyr. Again, the IR spectrum of each diastereomer does not depend on the probe position; again, c-LTyr-LTyr and c-LTyr-DTyr show similar spectroscopic signatures in the region of $v(\mathrm{NH})$, with three congested bands at 3400, 3412, and $3424 \mathrm{~cm}^{-1}$ for c-LTyr-LTyr and a doublet at 3394- $3432 \mathrm{~cm}^{-1}$ accompanied by a shoulder at $3417 \mathrm{~cm}^{-1}$ for c-LTyr-DTyr. The spectra of c-Tyr-Tyr only differ from that of c-Phe-Phe by the presence of a narrow band at $3656 \pm 1 \mathrm{~cm}^{-1}$, characteristic of a free $v(\mathrm{OH})$ stretch. The spectra of $\mathrm{B}_{\mathrm{c}-\mathrm{LL}}$ and $\mathrm{B}_{\mathrm{c}-\mathrm{LD}}$ can be interpreted in terms of "folded-extended structures" identical to those calculated for c-Phe-Phe. They compare well to that simulated for the $\mathrm{c}^{-\mathrm{g}^{+}} \mathrm{g}^{-}$structures, in particular, the most stable of them $c-g_{\text {LII }}^{+} g_{\mathrm{LI}}^{-}$and $c-g_{\mathrm{LI}}^{+} \mathrm{g}_{\mathrm{DI}}^{-}$shown in Fig. 3. The sharp bands at $3656 \mathrm{~cm}^{-1}$ is the superposition of the two free $v(\mathrm{OH})$. The assignment of the triplet in the 3400$3412 \mathrm{~cm}^{-1}$ range parallels that described for cyclo Phe-Phe. We therefore assign the broad absorption to the superposition of $\mathrm{c}-\mathrm{g}_{\mathrm{L}}^{+} \mathrm{g}_{\mathrm{SL}}^{-}$structures differentiating only by the tyrosyl $\mathrm{OH}$ orientation.

The major difference between the two diastereoisomers, for both c-Tyr-Tyr and c-Phe-Phe, is the energy difference between the bound and free $v(\mathrm{NH})$ stretches, which is always larger in c-LL than c-LD (experimental value of $23 \mathrm{~cm}^{-1} v s .31 \mathrm{~cm}^{-1}$ for c-Phe-Phe and 12 vs. $38 \mathrm{~cm}^{-1}$ for cycloTyr-Tyr. This difference reflects the 
stronger NH... $\pi$ interaction in cLD. It should be noted that scaled harmonic frequencies satisfactorily account for the frequency gap between c-LL and c-LD, for both studied molecules.

c- $g^{+} g^{+}$Structures: The IR-UV spectrum of c-LTyr-LTyr recorded with the probe at the origin or any of the narrow transitions transition is shown in Fig. 7. Compared to the spectra described above, the free $v(\mathrm{OH})$ stretch is slightly shifted down in energy $\left(3648 \mathrm{~cm}^{-1}\right)$. The doublet at 3409 and $3428 \mathrm{~cm}^{-1}$ is similar to those described for $v(\mathrm{NH})$ in the other systems and points at a dissymmetric structure with non- equivalent benzyls. Last, the intense peak at $3554 \mathrm{~cm}^{-1}$ appears in the range of bound $v(\mathrm{OH})$ stretches. This spectral pattern is very well reproduced by that calculated for $\mathrm{c}-\mathrm{g}_{\mathrm{LI}}^{+} \mathrm{g}_{\mathrm{LI}}^{+}$, which is the only structure that reproduces the feature at 3554 $\mathrm{cm}^{-1}$ assigned to the bound $\mathrm{OH}$. The band at $3648 \mathrm{~cm}^{-1}$ is assigned to the free $v(\mathrm{OH})$ calculated at $3649 \mathrm{~cm}^{-1}$, which is slightly shifted down in energy due to its role as a hydrogen bond donor. The band at $3409 \mathrm{~cm}^{-1}$ is assigned to the strong asymmetric $v(\mathrm{NH})$ stretch overlapped with the weak symmetric combination, calculated at $3413 / 3414 \mathrm{~cm}^{-1}$. Finally, the band at $3428 \mathrm{~cm}^{-1}$ is assigned to an overtone or combination band.

\subsection{Localization of the Electronic Transition}

\subsubsection{Experimental spectra}

c-LPhe-LPhe: The $0_{0}^{0}$ transition of singly ${ }^{13} \mathrm{C}$-substituted c-Phe-Phe, shown in the inset of

Fig. 5, is split by $\sim 4 \mathrm{~cm}^{-1}$. This splitting is the convolution of the exciton splitting due to the coupling between the locally excited states and the site splitting due to the dissymmetry of the molecule and the non-equivalence of the benzyl rings. Because of the relatively large distance between the chromophores, the exciton splitting is smaller than the experimental resolution in similar systems such as 1,3-diphenoxymethane[43] or bis-phenoxymethane[30] and is negligible. The different intensities within the doublet confirm that c-LPhe-DPhe is not a symmetrical conformation. The observed spectrum is therefore characteristic of a bichromophoric system with non-equivalent subunits and well-localized transitions. Indeed, the change in electron density between $\mathrm{S}_{0}$ and $\mathrm{S}_{1}$ electronic states (vertical transition) reflects the localized character of the excitation, both in c-Phe-Phe and c-Tyr-Tyr (see Fig. 8). The changes in electron density are mainly located on a single benzene ring, pointing at the localization of the transition. 


\subsubsection{Simulated spectra}

Optimization of the first electronic excited state and simulation of the $\mathrm{S}_{0} \rightarrow \mathrm{S}_{1}$ transition of the $\mathrm{c}-\mathrm{g}_{\mathrm{L}}^{+} \mathrm{g}_{\mathrm{L}}^{-}$conformer of c-LPhe-LPhe, introducing both Franck-Condon and Hertzberg terms, confirms the experimental findings. After shifting down the calculated origin by $\sim 2230 \mathrm{~cm}^{-1}$ to scale it on the experimental value, excellent agreement between simulated and experimental vibronic patterns is obtained, as shown in

Fig. 5 The intense band at $+532 \mathrm{~cm}^{-1}$ is assigned to the Hertzberg-Teller allowed transition, akin to $v_{6}$ of benzene.

a)

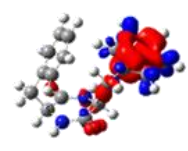

c) $5,02 \mathrm{eV}$

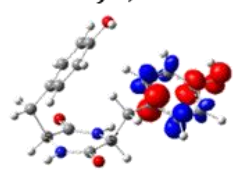

b) $4,99 \mathrm{eV}$

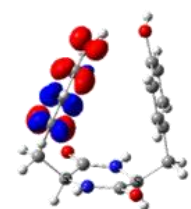

d) $5,04 \mathrm{eV}$

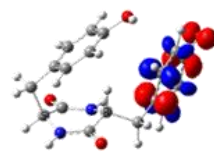

Fig. 8 Difference in electron density between $S_{0}$ and $S_{I}$ in the structures corresponding to the experiment for the folded-extended forms of a) c-LPhe-LPhe $c-g_{L}^{+} g_{L}^{-}$b) c-LTyr-LTyr c$g_{L I I}^{+} g_{L I}^{-}$c) c-LTyr-DTyr c- $g_{L I}^{+} g_{D I}^{-}$and the stacked structure of d) c-LTyr-LTyr c- $g_{L I}^{+} g_{L I}^{+}$. The electron density isovalue is 0.004 a.u. The electron density difference is coded in blue for an increase upon electronic excitation and red for a decrease. The $S_{0} \rightarrow S_{1}$ energy is given in parentheses for the different conformers of c-Tyr-Tyr

The geometry of the $S_{1}$ state is very close to that of the ground state, apart from a minor rotation of the $g_{S}^{-}$extended residue. This minor change manifests itself by the presence of a weak vibrational progression built on a $25 \mathrm{~cm}^{-1}$ mode, assigned to the $v_{1}\left(36 \mathrm{~cm}^{-1}\right)$ mode involving this rotation.

c-LTyr-LTyr: The same ${ }^{13} \mathrm{C}$ experiments were not possible for c-Tyr-Tyr because of weak intensity and spectral congestion. Instead, we have compared the calculated vertical $\mathrm{S}_{0}-\mathrm{S}_{1}$ energies for the conformers to which the experimental spectrum is assigned (see Fig. 8). The order of the calculated $\mathrm{S}_{0}-\mathrm{S}_{1}$ energies, c- $\mathrm{g}_{\mathrm{LI}}^{+} \mathrm{g}_{\mathrm{LII}}^{+}<\mathrm{c}-\mathrm{g}_{\mathrm{L}}^{+} \mathrm{g}_{\mathrm{D}}^{-}$ $<\mathrm{c}-\mathrm{g}_{\mathrm{L}}^{+} \mathrm{g}_{\mathrm{L}}^{-}$, is in qualitative agreement with the experiment. In particular, the 35274 
$\mathrm{cm}^{-1}$ band assigned to the origin of $\mathrm{c}^{-} \mathrm{g}_{\text {LI }}^{+} \mathrm{g}_{\text {LII }}^{+}$is shifted down in energy relative to the origin of the tyrosine conformers ( 35491 to $35650 \mathrm{~cm}^{-1}$ ).[63] This is reminiscent of the $\mathrm{S}_{0}-\mathrm{S}_{1}$ transition of the dipeptide tyrosyl-glycine, which is red-shifted by $\sim 400$ $\mathrm{cm}^{-1}$ relative to tyrosine when the hydroxyl group is not free.[71]

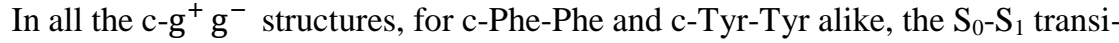
tion is of $\pi \pi^{*}$ nature and is localized on the extended $\mathrm{g}^{-}$aromatic ring. IR spectroscopy of the electronic excited state [72,73] has been proposed recently as a tool for determining the localization of the energy.[74] The systems studied here should show two families of $\mathrm{NH}$ stretches, localized on the locally excited aromatic ring or not, with frequencies characteristic of the ground and electronic excited states. However, the lifetimes are not long enough for this experiment to be possible with ns lasers. It would be interesting to perform this experiment on DKP peptides with chromophores with longer $\mathrm{S}_{1}$ lifetimes.

\subsection{Localization of the Charge in the Cation}

The double resonance spectrum of the c-LPhe-LPhe radical cation does not show any transition, probably because the $v(\mathrm{NH})$ stretches are shifted down out of the accessible frequency range. The double resonance spectrum of the c-LTyr-LTyr cation is recorded with the UV probe set at the same positions as for the neutral ground state. The obtained spectra do not depend on the position of the probe. Monitoring the depletion of the parent at $\mathrm{m} / z 326$ or the intensity of the fragment resulting from $\mathrm{C}_{\alpha}-\mathrm{C}_{\beta}$ cleavage at $\mathrm{m} / z 220$ also leads to the same spectra. This observation indicates that the measured spectra are due to structures populated after intramolecular vibrational energy redistribution (IVR). The same independence of the spectrum upon the probe wavelength is observed for c-LTyr-DTyr. The experimental spectra shown in Fig. 9 is analyzed in what follows at the light of the charge density calculations described in Section 3.2.2.

c-LTyr-DTyr: The experimental spectrum (Fig. 9) shows excellent agreement with that simulated for $\mathrm{c}_{\text {ion }}-\mathrm{g}_{\mathrm{LI}}^{+} \mathrm{t}_{\mathrm{DI}}$ and reflects the dissymmetry of the phenol rings, which was apparent from the charge distribution (Section 3.3.2). The band at 3642 $\mathrm{cm}^{-1}$ corresponds to the free $\mathrm{v}(\mathrm{OH})$ of the neutral $\mathrm{g}_{\mathrm{LI}}^{+}$ring calculated at $3638 \mathrm{~cm}^{-1}$. The intense band at $3572 \mathrm{~cm}^{-1}$ is assigned to the free $v(\mathrm{OH})$ of the charged $t_{D I}$ ring, calculated at $3586 \mathrm{~cm}^{-1}$. This value is close to that observed for the cyclo LtyrosylLproline radical cation $\left(3563 \mathrm{~cm}^{-1}\right)$, where the charge is necessarily localized on Tyr.[23] It is also close to that of the phenol:argon cation $\left(3535 \mathrm{~cm}^{-1}\right)$.[75] Lastly, the weak band at $3410 \mathrm{~cm}^{-1}$ is assigned to the two $v(\mathrm{NH})$ stretches calculated at identical values $\left(3400 \mathrm{~cm}^{-1}\right)$. The NH... $\pi$ interaction observed in the neutral is absent in the cation, which makes the two $\mathrm{NH}$ equivalent with identical $v(\mathrm{NH})$ stretch frequencies, close to that of the $v(\mathrm{NH})$ of the neutral ground state, due to the very small charges on the two NH. 
c-LTyr-LTyr: The spectrum of c-LTyr-LTyr is more complex than that of c-LTyr-DTyr and is accounted for by the contribution of two structures. The first one, $c_{\text {ion }}-\mathrm{g}_{\text {LII }}^{+} \mathrm{t}_{\mathrm{LII}}$, is similar to that described for c-LTyr-DTyr. The only difference relative to c-LTyr-DTyr is a small redshift $\left(7 \mathrm{~cm}^{-1}\right)$ of the free $v(\mathrm{OH})$ of the neutral $\mathrm{g}_{\mathrm{LII}}^{+}$ring, observed at $3635 \mathrm{~cm}^{-1}$ and calculated at $3630 \mathrm{~cm}^{-1}$. The free $\mathrm{v}(\mathrm{OH})$ of the "charged" $t_{\mathrm{LII}}$ ring appears at a similar value $\left(3569 \mathrm{~cm}^{-1}\right)$ as in c-LTyr-DTyr within the experimental error and is calculated at $3590 \mathrm{~cm}^{-1}$. The $v(\mathrm{NH})$ stretches are also slightly shifted down in frequency $\left(3394 \mathrm{~cm}^{-1}\right)$ relative to c-LTyr-DTyr. The second structure, $\mathrm{c}_{\mathrm{ion}}-\mathrm{g}_{\mathrm{LI}}^{+} \mathrm{g}_{\mathrm{LI}}^{+}$, is the hydrogen-bonded structure. As the hydrogen bond also influences the frequency of the donor, the free $v(\mathrm{OH})$ is slightly shifted down in energy $\left(3619 \mathrm{~cm}^{-1}\right)$ relative to that of $\mathrm{c}_{\text {ion }}-\mathrm{g}_{\text {LII }}^{+} \mathrm{t}_{\mathrm{LII}}$ and is calculated at $3613 \mathrm{~cm}^{-1}$. The large intensity of the band at $3394 \mathrm{~cm}^{-1}$ is explained by the superposition of the intense bound $v(\mathrm{OH})$ of $\mathrm{c}_{\mathrm{ion}}-\mathrm{g}_{\mathrm{LI}}^{+} \mathrm{g}_{\mathrm{LI}}^{+}$, superimposed with the $v(\mathrm{NH})$ stretches of $\mathrm{c}_{\text {ion }}-\mathrm{g}_{\mathrm{LII}}^{+} \mathrm{t}_{\mathrm{LII}}$ and $\mathrm{c}_{\text {ion }}-\mathrm{g}_{\mathrm{LI}}^{+} \mathrm{g}_{\mathrm{LI}}^{+}$, all calculated at $3399 \pm 3 \mathrm{~cm}^{-1}$. Lastly, the free $v(\mathrm{OH})$ stretch shows a shoulder at its low-energy side that may be assigned to a hot band, as often observed in photo-cations of cyclic molecules.[28]

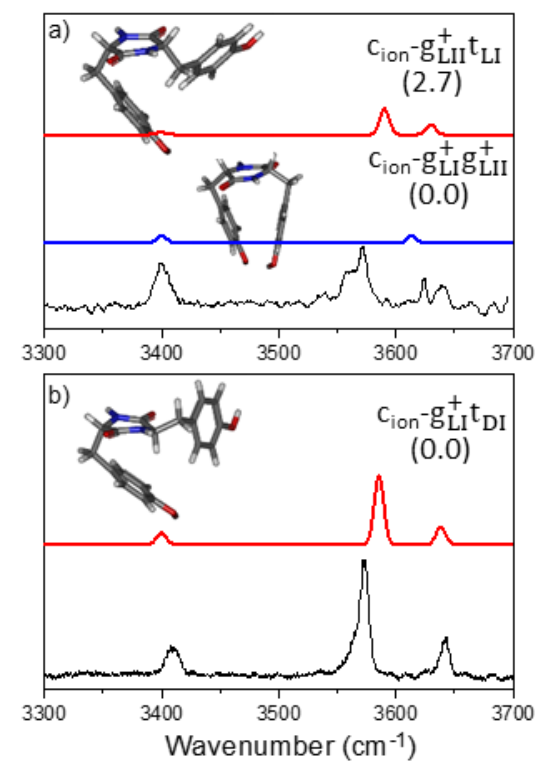

Fig. 9 Experimental and simulated spectrum of the ionic state of a) c-LTyr-LTyr and b) c-LTyr-DTyr together with corresponding calculated structures. The relative Gibbs energy is given in parentheses in $\mathrm{kcal} / \mathrm{mol}$. Adapted and reproduced from Ref. 22 with permission from the Royal Society of Chemistry

The potential energy surface of the cation reflects that of the neutral: IVR populates one conformer only for c-LTyr-DTyr, while two different structures are observed for c-LTyr-LTyr, despite their energy difference. Interestingly, the stereo- 
selectivity is preserved in the cation. This contrast with other cyclic systems bearing two chiral centers. In molecules where chirality is due to an asymmetric nitrogen atom, the nitrogen becomes planar upon ionization because it bears the positive charge.[28] As the results, the effects of stereochemistry are lost. Opening of the cycle upon ionization also results in a loss of stereochemical effects.[27]

\section{Conclusion and Perspectives}

Compared to the linear peptides, DKP peptides are rigid structures, with only one conformation of the DKP ring and the substituent orientation for the two diastereomers of c-Phe-Phe and for c-LTyr-DTyr, and two for c-LTyr-LTyr. This contrasts with the parent amino acids, with 6 conformers for jet-cooled phenylalanine and 12 for tyrosine. $[67,63]$ None of the structure found is symmetrical. The asym-

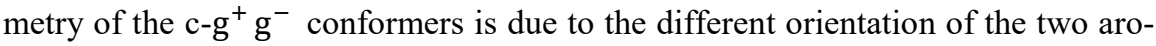
matic rings that are folded and extended respectively. As a result, the molecule cannot be seen like a meso compound and $\mathrm{c}-\mathrm{g}_{\mathrm{L}}^{+} \mathrm{g}_{\mathrm{D}}^{-}$is mirror image to $\mathrm{c}-\mathrm{g}_{\mathrm{D}}^{+} \mathrm{g}_{\mathrm{L}}^{-}$. Going from one enantiomer to the other only requires large amplitude motions inverting the folded and extended positions. At room temperature, interconversion is easy and the two transient enantiomers cannot be distinguished, unless embedded in special environments like a chiral liquid crystal, in which NMR experiments should discriminate between them.[76,77]

It should be noticed too that folded-extended structures are systematically found in many neutral DKP peptides, in condensed or in the gas phase, unless one introduces an interaction stronger than the $\mathrm{NH} . . . \pi$ or $\mathrm{CH} \ldots \ldots \pi$ that are responsible for the folded-extended structures.[23,25,21,19] In the case of c-LTyr-LTyr reported here, the interaction is an $\mathrm{OH}$... O hydrogen bond. Future perspectives would be to modulate this interaction by changing the distance between the donor and the acceptor, for example by replacing one tyrosine by homo tyrosine. Adding a solvent molecule for bridging the two hydroxyls would be interesting too.[78,79] We have reached the same conclusion concerning the predominance of folded-extended structures for protonated DKP peptides isolated in a room-temperature ion trap. It would be interesting to test this hypothesis further by resorting to cryogenic ion traps for isolating the most stable structures of DKP dipeptides and studying the relationship between their structure and their photoreactivity. Indeed, cryogenic ion traps coupled with IR or UV laser spectroscopy have proven to be a powerful tool for studying chiral recognition in clusters of chiral molecules.[80,81]

Both experimental and theoretical results point out at the localization of the electronic excitation, and most of the charge for the cation, on one aromatic ring. The coupling between the two moieties is therefore limited. However, more coupling effects between the two chromophores should be observed in electronic circular dichroism.[82,83] 
Finally, calculations indicate that the c-LL structure is more stable than the cLD, for both studied molecules. Although one cannot draw general conclusions from two systems only, this observation agrees well with the so-called homochirality of life.

\section{References}

1. Borthwick AD (2012) 2,5-Diketopiperazines: Synthesis, Reactions, Medicinal Chemistry, and Bioactive Natural Products. Chemical Reviews 112 (7):3641-3716. doi:10.1021/cr200398y

2. Basiuk VA, Gromovoy TY (1994) The Gas Solid-Phase 2,5-Dioxopiperazine Synthesis Cyclization of Vaporous Dipeptides on Silica Surface. Collection of Czechoslovak Chemical Communications 59 (2):461-466. doi:10.1135/cccc19940461

3. Berset J-D, Ochsenbein N (2012) Stability considerations of aspartame in the direct analysis of artificial sweeteners in water samples using high-performance liquid chromatography-tandem $\begin{array}{lllll}\text { mass } & \text { spectrometry (HPLC-MS/MS). } & \text { Chemosphere } & 88 & \text { (5):563-569. }\end{array}$ doi:10.1016/j.chemosphere.2012.03.030

4. Lin SY, Wang SL (2012) Advances in simultaneous DSC-FTIR microspectroscopy for rapid solid-state chemical stability studies: Some dipeptide drugs as examples. Advanced Drug Delivery Reviews 64 (5):461-478. doi:10.1016/j.addr.2012.01.009

5. Sinha S, Srivastava R, De Clereq E, Singh RK (2004) Synthesis and antiviral properties of arabino and ribonucleosides of 1,3-dideazaadenine, 4-nitro-1,3-dideazapurine and diketopiperazine. Nucleosides Nucleotides \& Nucleic Acids 23 (12):1815-1824. doi: $10.1081 / \mathrm{ncn}-200040614$

6. Grande F, Garofalo A, Neamati N (2008) Small molecules anti-HIV therapeutics targeting CXCR4. Current Pharmaceutical Design 14 (4):385-404

7. Walchshofer N, Sarciron ME, Garnier F, Delatour P, Petavy AF, Paris J (1997) Anthelmintic activity of 3,6-dibenzyl-2,5-dioxopiperazine, cyclo(L-Phe-L-Phe). Amino Acids 12 (1):41-47. doi: $10.1007 / \mathrm{bf} 01373425$

8. Danda H (1991) Essential factors in asymmetric hydrocyanation catalyzed by cyclo (-(R)-Phe(R)-His-). Synlett 1991 (04):263-264

9. Tanaka K, Mori A, Inoue S (1990) The cyclic dipeptide cyclo [(S)-phenylalanyl-(S)-histidyl] as a catalyst for asymmetric addition of hydrogen cyanide to aldehydes. The Journal of Organic Chemistry 55 (1):181-185

10. Jeon J, Shell MS (2014) Self-Assembly of Cyclo-diphenylalanine Peptides in Vacuum. Journal of Physical Chemistry B 118 (24):6644-6652. doi:10.1021/jp501503x

11. Jaworska M, Jeziorna A, Drabik E, Potrzebowski MJ (2012) Solid State NMR Study of Thermal Processes in Nanoassemblies Formed by Dipeptides. Journal of Physical Chemistry C 116 (22):12330-12338. doi:10.1021/jp302616n

12. Gross E (2012) The Peptides Analysis, Synthesis, Biology: Modern Techniques of Conformational Structural, and Configurational Analysis. Elsevier,

13. Sletten E (1970) Conformation of Cyclic Dipeptides . Crystal and Molecular Structures Of Cyclo-D-Alanyl-L-Alanyl And Cyclo-L-Alanyl-L-Alanyl (3,6-Dimethylpiperazine-2,5Dione). Journal of the American Chemical Society 92 (1):172-177. doi:10.1021/ja00704a028

14. Carlson KL, Lowe SL, Hoffmann MR, Thomasson KA (2005) Theoretical UV circular dichroism of aliphatic cyclic dipeptides. Journal of Physical Chemistry A 109 (24):5463-5470. doi: $10.1021 / \mathrm{jp} 046580 \mathrm{u}$ 
15. Milne PJ, Oliver DW, Roos HM (1992) Cyclodipeptides - Structure and Conformation of Cyclo(Tyrosyl Prolyl). J Cryst Spectrosc 22 (6):643-649. doi:Doi 10.1007/Bf01160980

16. Kopple KD, Marr DH (1967) Conformation of cyclic peptides. The folding of cyclic dipeptides containing an aromatic side chain. Journal of the American Chemical Society 89 (24):61936200. doi:10.1021/ja01000a035

17. Lin C-F, Webb LE (1973) Crystal structures and conformations of the cyclic dipeptides cyclo(Glycyl-L-tyrosyl) and cyclo-(L-seryl-L-tyrosyl) Monohydrate. Journal of the American Chemical Society 95 (20):6803-6811. doi:10.1021/ja00801a046

18. Benedetti E, Marsh RE, Goodman M (1976) Conformational studies on peptides. X-ray structure determinations of six N-methylated cyclic dipeptides derived from alanine, valine, and phenylalanine. Journal of the American Chemical Society 98 (21):6676-6684 doi: $10.1021 / \mathrm{ja} 00437 \mathrm{a} 041$

19. Gdaniec M, Liberek B (1986) Structure of Cyclo(-L-Phenylalanyl-L-Phenylalanyl-). Acta Crystallographica Section C-Crystal Structure Communications 42:1343-1345. doi: $10.1107 / \mathrm{s} 0108270186092338$

20. Fleischhauer J, Grotzinger J, Kramer B, Kruger P, Wollmer A, Woody RW, Zobel E (1994) Calculation of the Circular-Dichroism Spectrum of Cyclo(L-Tyr-L-Tyr) Based on a MolecularDynamics Simulation. Biophysical Chemistry 49 (2):141-152. doi:10.1016/03014622(93)e0065-d

21. Alata I, Perez-Mellor A, Ben Nasr F, Scuderi D, Steinmetz V, Gobert F, Jaidane NE, Zehnacker-Rentien A (2017) Does the Residues Chirality Modify the Conformation of a CycloDipeptide? Vibrational Spectroscopy of Protonated Cyclo-diphenylalanine in the Gas Phase. Journal of Physical Chemistry A 121 (38):7130-7138. doi:10.1021/acs.jpca.7b06159

22. BenNasr F, Perez-Mellor A, Alata I, Lepere V, Jaidane N-E, Zehnacker A (2018) Stereochemistry-dependent hydrogen bonds stabilise stacked conformations in jet-cooled cyclic dipeptides: (LD) vs. (LL) cyclo tyrosine-tyrosine. Faraday Discussions. doi:10.1039/c8fd00079d

23. Pérez Mellor A, Alata I, Zehnacker A (To be published) Conformational landscape of diastereomer cyclic dipeptide: Ir spectroscopy of jet-cooled cyclo LTyr-LPro vs. cyclo LTyrDPro.

24. Perez-Mellor A, Alata I, Lepère V, Zehnacker A (2018) Chirality effects in the structures of jet-cooled bichromophoric dipeptides. Journal of Molecular Spectroscopy 349: 71-84

25. Perez-Mellor A, Zehnacker A (2017) Vibrational circular dichroism of a 2,5-diketopiperazine (DKP) peptide: Evidence for dimer formation in cyclo LL or LD diphenylalanine in the solid state. Chirality 29 (2):89-96. doi:10.1002/chir.22674

26. Bouchet A, Klyne J, Ishiuchi SI, Dopfer O, Fujii M, Zehnacker A (2018) Stereochemistrydependent structure of hydrogen-bonded protonated dimers: the case of 1-amino-2-indanol. Physical Chemistry Chemical Physics 20 (18):12430-12443. doi:10.1039/c8cp00787j

27. Bouchet A, Klyne J, Piani G, Dopfer O, Zehnacker A (2015) Diastereo-Specific Conformational Properties of Neutral, Protonated and Radical Cation Forms of (1R,2S)-cis and (1R,2R)-trans Amino-Indanol by Gas Phase Spectroscopy. Physical Chemistry Chemical Physics 17:25809-25821. doi:10.1039/C5CP00576K

28. Mahjoub A, Chakraborty A, Lepere V, Le Barbu-Debus K, Guchhait N, Zehnacker A (2009) Chirality-dependent hydrogen bond direction in jet-cooled (S)-1,2,3,4-tetrahydro-3isoquinoline methanol (THIQM): IR-ion dip vibrational spectroscopy of the neutral and the ion. Physical Chemistry Chemical Physics 11 (25):5160-5169

29. Alauddin M, Gloaguen E, Brenner V, Tardivel B, Mons M, Zehnacker-Rentien A, Declerck V, Aitken DJ (2015) Intrinsic Folding Proclivities in Cyclic -Peptide Building Blocks: Configuration and Heteroatom Effects Analyzed by Conformer-Selective Spectroscopy and Quantum Chemistry. Chemistry-a European Journal 21 (46):16479-16493. doi:10.1002/chem.201501794 
30. Zehnacker A, Lahmani F, Breheret E, Desvergne JP, BouasLaurent H, Germain A, Brenner V, Millie P (1996) Laser induced fluorescence of jet-cooled non-conjugated bichromophores: Bisphenoxymethane and bis-2,6-dimethylphenoxymethane. Chemical Physics 208 (2):243-257

31. Lahmani F, Zehnacker A, Desvergne JP, Bouas-Laurent H, Colomes M, Kruger A (1998) Fluorescence emission in fluid solution and supersonic jet of symmetrical bisbenzenes incorporating a three membered flexible chain. Journal of Photochemistry and Photobiology A-Chemistry 113 (3):203-212

32. Baquero EE, James WH, III, Choi TH, Jordan KD, Zwier TS (2008) Single Conformation Spectroscopy of a Flexible Bichromophore: 3-(4-Hydroxyphenyl)-N-benzylpropionamide. Journal of Physical Chemistry A 112 (44):11115-11123. doi:10.1021/jp806787p

33. Buchanan EG, Gord JR, Zwier TS (2013) Solvent Effects on Vibronic Coupling in a Flexible Bichromophore: Electronic Localization and Energy Transfer induced by a Single Water Molecule. Journal of Physical Chemistry Letters 4 (10):1644-1648. doi:10.1021/jz400641p

34. Pillsbury NR, Kidwell NM, Nebgen B, Slipchenko LV, Douglass KO, Cable JR, Plusquellic DF, Zwier TS (2014) Vibronic coupling in asymmetric bichromophores: Experimental investigation of diphenylmethane-d(5). Journal of Chemical Physics 141 (6). doi:10.1063/1.4892344

35. Walsh PS, Buchanan EG, Gord JR, Zwier TS (2015) Binding water to a PEG-linked flexible bichromophore: IR spectra of diphenoxyethane-(H2O)(n) clusters, n=2-4. Journal of Chemical Physics 142 (15). doi:10.1063/1.4917305

36. Sen A, Bouchet A, Lepere V, Le Barbu-Debus K, Scuderi D, Piuzzi F, Zehnacker-Rentien A (2012) Conformational analysis of quinine and its pseudo enantiomer quinidine: a combined jet-cooled spectroscopy and vibrational circular dichroism study. The Journal of Physical Chemistry A 116 (32):8334-8344

37. Mengesha ET, Zehnacker-Rentien A, Sepiol J, Kijak M, Waluk J (2015) Spectroscopic Study of Jet-Cooled Deuterated Porphycenes: Unusual Isotopic Effects on Proton Tunneling. Journal of Physical Chemistry B 119 (6):2193-2203. doi:10.1021/jp505553z

38. Gloaguen E, de Courcy B, Piquemal JP, Pilmé J, Parisel O, Pollet R, Biswal HS, Piuzzi F, Tardivel B, Broquier M, Mons M (2010) Gas-Phase Folding of a Two-Residue Model Peptide Chain: On the Importance of an Interplay between Experiment and Theory. Journal of the American Chemical Society 132 (34):11860-11863. doi:doi: 10.1021/ja103996q

39. Tanabe S, Ebata T, Fujii M, Mikami N (1993) OH Stretching Vibrations of Phenol(H2O)n(n=1-3) Complexes Observed by Ir-Uv Double-Resonance Spectroscopy. Chem Phys Lett 215 (4):347-352

40. Pribble RN, Zwier TS (1994) Size-Specific Infrared-Spectra of Benzene-( $\left.\mathrm{H}_{2} \mathrm{O}\right)_{(\mathrm{n})}$ Clusters ( $\mathrm{n}=1$ through 7) - Evidence for Noncyclic $\left(\mathrm{H}_{2} \mathrm{O}\right)_{(\mathrm{n})}$ Structures. Science 265 (5168):75-79

41. Ottiger P, Leutwyler S, Koppel H (2012) Vibrational quenching of excitonic splittings in Hbonded molecular dimers: The electronic Davydov splittings cannot match experiment. Journal of Chemical Physics 136 (17). doi:10.1063/1.4705119

42. Balmer FA, Kopec S, Koppel H, Leutwyler S (2017) Excitonic Splitting and Vibronic Coupling Analysis of the m-Cyanophenol Dimer. Journal of Physical Chemistry A 121 (1):73-87. doi:10.1021/acs.jpca.6b10416

43. Buchanan EG, Walsh PS, Plusquellic DF, Zwier TS (2013) Excitonic splitting and vibronic coupling in 1,2-diphenoxyethane: Conformation-specific effects in the weak coupling limit. Journal of Chemical Physics 138 (20). doi:10.1063/1.4807300

44. MacroModel version 9.8; ed. Schrödinger, LLC: New York, NY, 2010 (2010). MacroModel version 98; ed Schrödinger, LLC: New York, NY, 2010

45. Grimme S, Antony J, Ehrlich S, Krieg H (2010) A consistent and accurate ab initio parametrization of density functional dispersion correction (DFT-D) for the 94 elements H-Pu. Journal of Chemical Physics 132 (15). doi:10.1063/1.3382344

46. Grimme S, Ehrlich S, Goerigk L (2011) Effect of the Damping Function in Dispersion Corrected Density Functional Theory. Journal of Computational Chemistry 32 (7):1456-1465. doi: $10.1002 / j c c .21759$ 
47. Frisch MJ, Pople JA, Binkley JS (1984) Self-Consistent Molecular-Orbital Methods .25. Supplementary Functions for Gaussian-Basis Sets. Journal of Chemical Physics 80 (7):32653269. doi:10.1063/1.447079

48. Lepere V, Le Barbu-Debus K, Clavaguera C, Scuderi D, Piani G, Simon A-L, Chirot F, MacAleese L, Dugourd P, Zehnacker A (2016) Chirality-dependent structuration of protonated or sodiated polyphenylalanines: IRMPD and ion mobility studies. Physical Chemistry Chemical Physics 18 (3):1807-1817. doi:10.1039/c5cp06768e

49. Reed AE, Curtiss LA, Weinhold F (1988) Intermolecular interactions for a natural bond orbital, donor-acceptor viewpoint. Chemical Reviews 88 (6):899-926

50. Chai JD, Head-Gordon M (2008) Long-range corrected hybrid density functionals with damped atom-atom dispersion corrections. Physical Chemistry Chemical Physics 10 (44):6615-6620. doi:10.1039/b810189b

51. Jacquemin D, Perpete EA, Ciofini I, Adamo C (2011) Assessment of the omega B97 family for excited-state calculations. Theoretical Chemistry Accounts 128 (1):127-136. doi: $10.1007 / \mathrm{s} 00214-010-0783-\mathrm{x}$

52. Sen A, Lepere V, Le Barbu-Debus K, Zehnacker A (2013) How do Pseudoenantiomers Structurally Differ in the Gas Phase? An IR/UV Spectroscopy Study of Jet-Cooled Hydroquinine and Hydroquinidine. Chemphyschem : a European Journal of Chemical Physics and Physical Chemistry 14 (15):3559-3568. doi:10.1002/cphc.201300643

53. Johnson RD (2018) NIST Computational Chemistry Comparison and Benchmark Database NIST Standard Reference Database Number 101. http://cccbdb.nist.gov/. Accessed January 15 th 2019

54. Gloaguen E, Mons M (2015) Isolated Neutral Peptides. In: Rijs AM, Oomens J (eds) GasPhase Ir Spectroscopy and Structure of Biological Molecules, vol 364. Topics in Current Chemistry-Series. pp 225-270. doi:10.1007/128_2014_580

55. Plowright RJ, Gloaguen E, Mons M (2011) Compact Folding of Isolated Four-Residue Neutral Peptide Chains: H-Bonding Patterns and Entropy Effects. Chemphyschem 12 (10):1889-1899. doi: $10.1002 /$ cphc. 201001023

56. Gerhards M, Unterberg C (2002) Structures of the protected amino acid Ac-Phe-OMe and its dimer: A beta-sheet model system in the gas phase. Physical Chemistry Chemical Physics 4 (10): 1760-1765. doi:10.1039/b110029g

57. Bloino J, Barone V (2012) A second-order perturbation theory route to vibrational averages and transition properties of molecules: General formulation and application to infrared and vibrational circular dichroism spectroscopies. Journal of Chemical Physics 136 (12):124108 doi:10.1063/1.3695210

58. Bloino J, Baiardi A, Biczysko M (2016) Aiming at an accurate prediction of vibrational and electronic spectra for medium-to-large molecules: An overview. International Journal of Quantum Chemistry 116 (21):1543-1574. doi:10.1002/qua.25188

59. Bloino J, Biczysko M, Barone V (2015) Anharmonic Effects on Vibrational Spectra Intensities: Infrared, Raman, Vibrational Circular Dichroism, and Raman Optical Activity. Journal of Physical Chemistry A 119 (49):11862-11874. doi:10.1021/acs.jpca.5b10067

60. Frisch MJ, Trucks GW, Schlegel HB, Scuseria GE, Robb MA, Cheeseman JR, Scalmani G, Barone V, Mennucci B, Petersson GA, Nakatsuji H, Caricato M, Li XJ, Hratchian HP, Izmaylov AF, Bloino J, Zheng G, Sonnenberg JL, Hada M, Ehara M, Toyota K, Fukuda R, Hasegawa J, Ishida M, Nakajima T, Honda Y, Kitao O, Nakai H, Vreven T, Montgomery J, J A. , Peralta JE, Ogliaro F, Bearpark M, Heyd JJ, Brothers E, Kudin KN, Staroverov VN, Kobayashi R, Normand J, Raghavachari K, Rendell A, Burant JC, Iyengar SS, Tomasi J, Coss M, Rega N, Millam JM, Klene M, Knox JE, Cross JB, Bakken V, Adamo C, Jaramillo J, Gomperts R, Stratmann RE, Yazyev O, Austin AJ, Cammi R, Pomelli C, Ochterski JW, Martin RL, Morokuma K, Zakrzewski VG, Voth GA, Salvador P, Dannenberg JJ, Dapprich S, Daniels AD, Farkas O, Foresman JB, Ortiz JV, Cioslowski J, Fox DJS (2009) Gaussian 09, Revision D.01. Gaussian Inc., Wallingford CT 
61. Urago H, Suga T, Hirata T, Kodama H, Unno M (2014) Raman Optical Activity of a Cyclic Dipeptide Analyzed by Quantum Chemical Calculations Combined with Molecular Dynamics Simulations. Journal of Physical Chemistry B 118 (24):6767-6774. doi:10.1021/jp503874z

62. Inokuchi Y, Kobayashi Y, Ito T, Ebata T (2007) Conformation of L-tyrosine studied by fluorescence-detected UV-UV and IR-UV double-resonance spectroscopy. Journal of Physical Chemistry A 111 (17):3209-3215. doi:10.1021/jp070163a

63. Shimozono Y, Yamada K, Ishiuchi S-i, Tsukiyama K, Fujii M (2013) Revised conformational assignments and conformational evolution of tyrosine by laser desorption supersonic jet laser spectroscopy. Physical Chemistry Chemical Physics 15 (14):5163-5175. doi:10.1039/c3cp43573c

64. James WH, III, Buchanan EG, Guo L, Geman SH, Zwier TS (2011) Competition between Amide Stacking and Intramolecular H Bonds in gamma-Peptide Derivatives: Controlling Nearest-Neighbor Preferences. Journal of Physical Chemistry A 115 (43):11960-11970. doi:10.1021/jp2081319

65. Martinez SJ, Alfano JC, Levy DH (1992) The Electronic Spectroscopy of the Amino-Acids Tyrosine and Phenylalanine in a Supersonic Jet. Journal of Molecular Spectroscopy 156 (2):421-430

66. Lee KT, Sung J, Lee KJ, Kim SK, Park YD (2002) Resonant two-photon ionization study of jet-cooled amino acid: L-phenylalanine and its monohydrated complex. Journal of Chemical Physics 116 (19):8251-8254. doi:10.1063/1.1477452

67. Hashimoto T, Takasu Y, Yamada Y, Ebata T (2006) Anomalous conformer dependent S-1 lifetime of L-phenylalanine. Chem Phys Lett 421 (1-3):227-231. doi:10.1016/j.cplett.2006.01.074

68. Boyarkin OV, Mercier SR, Kamariotis A, Rizzo TR (2006) Electronic spectroscopy of cold, protonated tryptophan and tyrosine. Journal of the American Chemical Society 128 (9):28162817. doi: $10.1021 / \mathrm{ja} 058383 \mathrm{u}$

69. Ishiuchi S, Wako H, Kato D, Fujii M (2017) High-cooling-efficiency cryogenic quadrupole ion trap and UV-UV hole burning spectroscopy of protonated tyrosine. Journal of Molecular Spectroscopy 332:45-51. doi:10.1016/j.jms.2016.10.011

70. Abo-Riziq AG, Crews B, Bushnell JE, Callahan MP, De Vries MS (2005) Conformational analysis of cyclo( Phe-Ser) by UV-UV and IR-UV double resonance spectroscopy and ab initio calculations. Mol Phys 103 (11-12):1491-1495. doi:10.1080/00268970500095923

71. Abo-Riziq A, Grace L, Crews B, Callahan MP, van Mourik T, de Vries MS (2011) Conformational Structure of Tyrosine, Tyrosyl-glycine, and Tyrosyl-glycyl-glycine by Double Resonance Spectroscopy. Journal of Physical Chemistry A 115 (23):6077-6087. doi:10.1021/jp110601w

72. Seurre N, Sepiol J, Lahmani F, Zehnacker-Rentien A, Le Barbu-Debus K (2004) Vibrational study of the S-0 and S-1 states of 2-naphthyl-1-ethanol/(water)(2) and 2-naphthyl-1ethanol/(methanol)(2) complexes by IR/UV double resonance spectroscopy. Physical Chemistry Chemical Physics 6 (19):4658-4664

73. Loquais Y, Gloaguen E, Habka S, Vaquero-Vara V, Brenner V, Tardivel B, Mons M (2015) Secondary Structures in Phe-Containing Isolated Dipeptide Chains: Laser Spectroscopy vs Quantum Chemistry. Journal of Physical Chemistry A 119 (23):5932-5941. doi: $10.1021 / \mathrm{jp} 509494 \mathrm{c}$

74. Scutelnic V, Prlj A, Zabuga A, Corminboeuf C, Rizzo TR (2018) Infrared Spectroscopy as a Probe of Electronic Energy Transfer. Journal of Physical Chemistry Letters 9 (12):3217-3223. doi:10.1021/acs.jpclett.8b01216

75. Fujii A, Sawamura T, Tanabe S, Ebata T, Mikami N (1994) Infrared dissociation spectroscopy of the $\mathrm{OH}$ stretching vibration of phenol-rare gas van der Waals cluster ions. Chem Phys Lett $225(1-3): 104-107$

76. Aroulanda C, Merlet D, Courtieu J, Lesot P (2001) NMR experimental evidence of the differentiation of enantiotopic directions in $\mathrm{C}-\mathrm{s}$ and $\mathrm{C}-2 \mathrm{v}$ molecules using partially oriented, 
chiral media. Journal of the American Chemical Society 123 (48):12059-12066. doi:10.1021/ja0116851

77. Emsley JW, Lesot P, Merlet D (2004) The orientational order and conformational distributions of the two enantiomers in a racemic mixture of a chiral, flexible molecule dissolved in a chiral nematic liquid crystalline solvent. Physical Chemistry Chemical Physics 6 (3):522-530. doi: $10.1039 / \mathrm{b} 312512 \mathrm{~b}$

78. Lahmani F, Douhal A, Breheret E, Zehnacker-Rentien A (1994) Solvation Effects in JetCooled 7-Hydroxyquinoline. Chem Phys Lett 220 (3-5):235-242

79. Bach A, Coussan S, Muller A, Leutwyler S (2000) Water-chain clusters: Vibronic spectra of 7-hydroxyquinoline center $\operatorname{dot}\left(\mathrm{H}_{2} \mathrm{O}\right)_{2}$. Journal of Chemical Physics 112 (3):1192-1203

80. Klyne J, Bouchet A, Ishiuchi S, Fujii M, Schneider M, Baldauf C, Dopfer O (2018) Probing chirality recognition of protonated glutamic acid dimers by gas-phase vibrational spectroscopy and first-principles simulations. Physical Chemistry Chemical Physics 20 (45):28452-28464. doi:10.1039/c8cp05855e

81. Fujihara A, Sato T, Hayakawa S (2014) Enantiomer-selective ultraviolet photolysis of temperature-controlled protonated tryptophan on a chiral crown ether in the gas phase. Chem Phys Lett 610:228-233. doi:10.1016/j.cplett.2014.07.045

82. Matile S, Berova N, Nakanishi K, Novkova S, Philipova I, Blagoev B (1995) Porphyrins Powerful Chromophores for Structural Studies by Exciton-Coupled Circular-Dichroism. Journal of the American Chemical Society 117 (26):7021-7022. doi:10.1021/ja00131a033

83. Hong A, Choi CM, Eun HJ, Jeong C, Heo J, Kim NJ (2014) Conformation-Specific Circular Dichroism Spectroscopy of Cold, Isolated Chiral Molecules. Angewandte ChemieInternational Edition 53 (30):7805-7808. doi:10.1002/anie.201403916 